\title{
TRANSGÊNICOS: COMO ESTES SÃO CONHECIDOS PELOS ALUNOS DE CIÊNCIAS BIOLÓGICAS?
}

\section{TRANSGENICS: HOW ARE THESE KNOWLEDGE BY STUDENTS IN BIOLOGICAL SCIENCES?}

Jane Elen Almeida Fragoso', Renata Fernandes de Matos*

${ }^{1}$ Biologia pela Universidade Estadual do Ceará

2 Professora do Curso de Ciências Biológicas da UECE/FECLI*renatafmatos@hotmail.com.

\section{Info}

Recebido: 03/2021

Publicado: $11 / 2021$

DOI: $10.37951 / 2358-260 X .2021 v 8 i 2.5643$

ISSN: 2358-260X

Palavras-Chave
OGMs. Melhoramento genético.
Associação com o cotidiano.
Keywords:
OGMs. Genetical enhancement.
Association with everyday life.

\begin{abstract}
Resumo
Os transgênicos são organismos geneticamente modificados obtidos mediante a inserção de material genético oriundo de outro organismo, geralmente, de uma espécie diferente. Apesar da polêmica que gira em torno dos transgênicos, grandes benefícios podem ser observados com sua utilização. Com o objetivo de identificar o conhecimento que alunos de um curso de Ciências Biológicas apresentam sobre os produtos transgênicos, foi desenvolvida uma pesquisa do tipo quali-quantitativa em uma instituição de ensino superior pertencente a Universidade Estadual do Ceará, na qual foram entrevistados 90 alunos. A coleta de dados se deu por meio da aplicação de um questionário, sendo os dados categorizados, transformados em porcentagens e
\end{abstract} apresentados na forma de gráficos e tabelas. Pelos resultados obtidos ficou claro que o tema transgênicos precisa ser melhor trabalhado no âmbito acadêmico, sendo identificadas deficiências na aprendizagem dos alunos. Dessa forma, é necessário que estratégias de aprendizado sejam desenvolvidas, sendo de grande viabilidade a associação dos conhecimentos com o dia a dia dos alunos.

\begin{abstract}
Transgenics are genetically modified organisms obtained by inserting genetic material from another organism, usually from a different species. Despite the controversy surrounding GMOs, great benefits can be seen with their use. In order to identify the knowledge that students of a Biological Sciences course present on transgenic products, a qualitative and quantitative research was developed in a higher education institution belonging to the State University of Ceará, in which 90 students were interviewed. Data collection took place through the application of a questionnaire, the data being categorized, transformed into percentages and presented in the form of graphs and tables. From the results obtained, it became clear that the topic of transgenics needs to be better addressed in the academic field, with deficiencies in student learning being identified. Thus, it is necessary that learning strategies are developed, and the association of knowledge with the students' daily lives is highly feasible.
\end{abstract}

\section{INTRODUÇÃO}

Os transgênicos são organismos geneticamente modificados (OGMs) obtidos com o uso dos métodos da Engenharia Genética. Para que estes sejam desenvolvidos, o organismo recebe uma ou mais sequências de DNA oriundas de outro organismo, o que, na maioria dos casos, envolve outra espécie. Dessa forma, o organismo obtido é caracterizado por apresentar um genoma modificado (SILVA, 2010).
Os OGMs podem ser definidos como toda entidade biológica cujo material genético (DNA ou RNA) foi alterado mediante a aplicação de técnicas moleculares, resultando em características que não poderiam ser obtidas naturalmente. A Engenharia Genética utilizada para obter os OGMs permite que genes individuais selecionados possam ser transferidos de um organismo para outro, o que é possível até mesmo entre espécies não relacionadas (MAPA, 2019). 
Muitas vezes a população tem uma concepção distorcida em relação ao conceito e a obtenção de transgênicos e OGMs, chegando, em diversos casos, a considerar estes como sinônimos (ZANINI, 2015). A literatura expressa que todo transgênico é um organismo que passou por modificações genéticas e, portanto, um OGM, porém, nem todo OGM é um transgênico, pois OGMs podem ser desenvolvidos sem a junção de material genético de organismos diferentes, sendo de grande relevância fazer a distinção entre esses (PEDRANCINI, 2009).

As principais espécies transgênicas cultivadas no Brasil são a soja (Glycine max), o milho (Zea mays) e o algodão (Gossypium hirsutum), os quais dão origem a produtos como o óleo de cozinha, extrato de soja, proteína texturizada, leite de soja, salsicha, margarina, massas, bolachas e cereais. Apesar da diversidade de produtos disponíveis para o consumo, existe uma grande polêmica em torno da segurança à saúde e ao meio ambiente, de forma que alguns apontam que estes podem ser maléficos e outros defendem que estes não causam riscos, sobretudo, à saúde (UDO, 2015).

Tendo em vista a segurança alimentar, é necessário destacar que o agravo à saúde humana pode ser incontável em tempo futuros. Pesquisas que envolvam os alimentos transgênicos e o ser humano devem ser incentivadas e desenvolvidas, de modo a fazer uma abordagem da relação entre esses. Nesse contexto, a tomada de decisão dos governantes também deve girar em torno do que cientificamente é comprovado, não interferindo no futuro da saúde humana ou da produção agrícola (FERREIRA, 2018).

Os produtos transgênicos são desenvolvidos com base em alterações que promovem o aparecimento de características desejadas, como, por exemplo, aumento do tamanho, resistência ao ataque de patógenos e melhora do teor nutricional. Esses alimentos podem ser utilizados no consumo direto ou como insumos para a produção de outros alimentos, estando presentes nos subprodutos. Dessa forma, os transgênicos tornaram-se produtos com grande importância socioeconômica (LACEY, 2009).

Após o início do desenvolvimento dos transgênicos, uma série de avanços foram observados, seja na própria forma de produção ou nos benefícios gerados à população. Contudo, é ainda necessário que estudos sejam desenvolvidos quanto aos impacto gerados e quanto ao conhecimento sobre tais produtos, o que deve ser foco principalmente nos cursos de nível superior em que o tema é abordado, pois estes produtos mostram-se cada vez mais expressivos (EMBRAPA, 2014).

Diante dessas informações, o presente trabalho tem por objetivo identificar o conhecimento que alunos de um curso de Ciências Biológicas apresentam sobre os produtos transgênicos.

\section{MATERIAL E MÉTODOS}

\section{Tipo de Pesquisa}

Foi desenvolvida uma pesquisa do tipo qualiquantitativa, a qual representa um método misto e abrange os pontos fortes de cada tipo de abordagem. Esse tipo de pesquisa proporciona uma maior compreensão das informações com as quais se trabalha, possibilitando conclusões robustas acerca do público estudado (CRESWELL, 2010).

A pesquisa apresenta também cunho descritivo, o qual tem por objetivo analisar, de forma aprofundada, as respostas apresentadas pelos entrevistados. Esse tipo de pesquisa é uma classificação da pesquisa cientifica, caracterizada por manter uma relação entre as variáveis propostas no estudo, podendo-se extrair informações consideráveis sobre o tema abordado (NÓBREGA, 2009).

\section{Sujeitos e Local da Pesquisa}


A pesquisa foi desenvolvida com alunos de um curso de Licenciatura em Ciências Biológicas, o qual é ofertado por uma Instituição de Ensino Superior pertencente a Universidade Estadual do Ceará, no estado do Ceará. A mesma apresenta sede em um município localizado no interior do referido estado.

O curso investigado apresenta nove semestres e, com o objetivo de obter conclusões que possam ser estendidas para todo o seu público, os nove semestres foram considerados na pesquisa. Dessa forma, de cada semestre tomou-se uma amostra de dez alunos, o que perfez um total de 90 entrevistados, adotando-se assim um número igual de alunos por semestre.

\section{Coleta de Dados}

Os dados foram coletados por meio da aplicação de um questionário semiestruturado composto por questões objetivas e subjetivas. O mesmo é um importante instrumento de coleta de dados, pois apresenta linguagem simples e direta, permitindo que o participante entenda de forma clara o que está sendo perguntado.

O questionário torna-se uma opção de grande viabilidade para esse tipo de pesquisa, configurando-se como uma técnica de investigação composta por indagações que são apresentadas por escrito aos entrevistados, resultando na obtenção de dados sobre conhecimentos, opiniões, sentimentos, interesses, expectativas e situações vivenciadas (GIL, 2012).

\section{Análise dos Dados}

Os dados foram analisados de forma técnica e específica. Para isto, os mesmos foram submetidos a análises da estatística descritiva, o que possibilitou que, a partir das informações coletadas, conclusões fossem obtidas para o conjunto populacional considerado na investigação.
Foram utilizadas as ferramentas do Microsoft

Office, destinando-se o Word para organização e análise das questões subjetivas e o Microsoft Excel para as questões objetivas. Para facilitar a visualização e interpretação dos resultados, realizou-se a categorização das respostas e a obtenção das porcentagens de indicação, sendo estas apresentadas na forma de gráficos e tabelas.

\section{RESULTADOS E DISCUSSÃO}

Ao buscar saber dos alunos se os mesmos já tinham ouvido falar sobre produtos transgênicos, pelos resultados obtidos foi possível identificar que a maioria dos entrevistados respondeu "sim", o que foi indicado por $95,6 \%$. Esse resultado mostra que os alunos do curso de Ciências Biológicas investigado, em sua grande maioria, já tiveram contato com o tema abordado, o que é de grande positividade quando se considera que estes necessitam conhecer sobre tal para sua profissão.

Contudo, existe ainda 4,4\% desse público que nunca ouviu falar sobre transgênicos, apesar de ser esse um tema atual e polêmico, sendo contemplado pelo meio acadêmico e também nas mídias de comunicação. Dessa forma, destaca-se que o aprendizado sobre temas dessa ordem é algo que contribui para a melhoria da visão quanto a temas diretamente relacionados a saúde e ao meio ambiente, melhorando os aspectos da condição da vida humana e do seu posicionamento (SCHWARTZMAN, 2018).

Ao perguntar aos alunos se existem diferenças entre transgênicos e OGMs, 56,7\% dos entrevistados responderam que "não" e 43,3\% que "sim". Essas informações mostram que, apesar dos alunos terem contato com o tema, como relatado anteriormente, uma porcentagem significativa destes não apresenta conhecimentos aprofundados a ponto de distinguir os transgênicos doa OGMs. 
Nesse contexto, vale ressaltar que o transgênico é caracterizado por apresentar genes oriundos de outros organismos, o que não é observado para todos os OGMs, implicando que muitos alunos não conhecem a diferença básica entre esses. Para que os transgênicos sejam de fato desenvolvidos, é necessário que os cientistas controlem as alteração decorrentes da presença do DNA exógeno, o que, após ser realizado a fundo, permite o lançamento do produto no mercado, identificando-se condições diferentes quando se trata de OGMs (EMBRAPA, 2020).

A falta de conhecimentos sobre os transgênicos pode ser atribuída ao fato dos alunos não terem visto o tema de forma aprofundada, seja durante as aulas no curso de Ciências Biológicas, ou mesmo na busca pelo complemento da informação no âmbito extra classe. A melhoria da educação pode assim ser considerada um grande aliado na aquisição e consolidação de informações biológicas, o que é fortemente capaz de influenciar o nível de conhecimento dos estudantes, bem como a vontade destes em persistir no aprendizado (VILLANI, 2009).

Ao se indagar os alunos sobre as vantagens do uso dos produtos transgênicos, foi possível obter os resultados presentes na Figura 1. As respostas obtidas foram bastante variadas, de forma que as mais citadas foram o "aumento da produtividade" e a "resistência a pragas", o que, de fato, são benefícios de grande importância econômica, favorecendo tanto os produtores dos transgênicos como os consumidores desses alimentos.

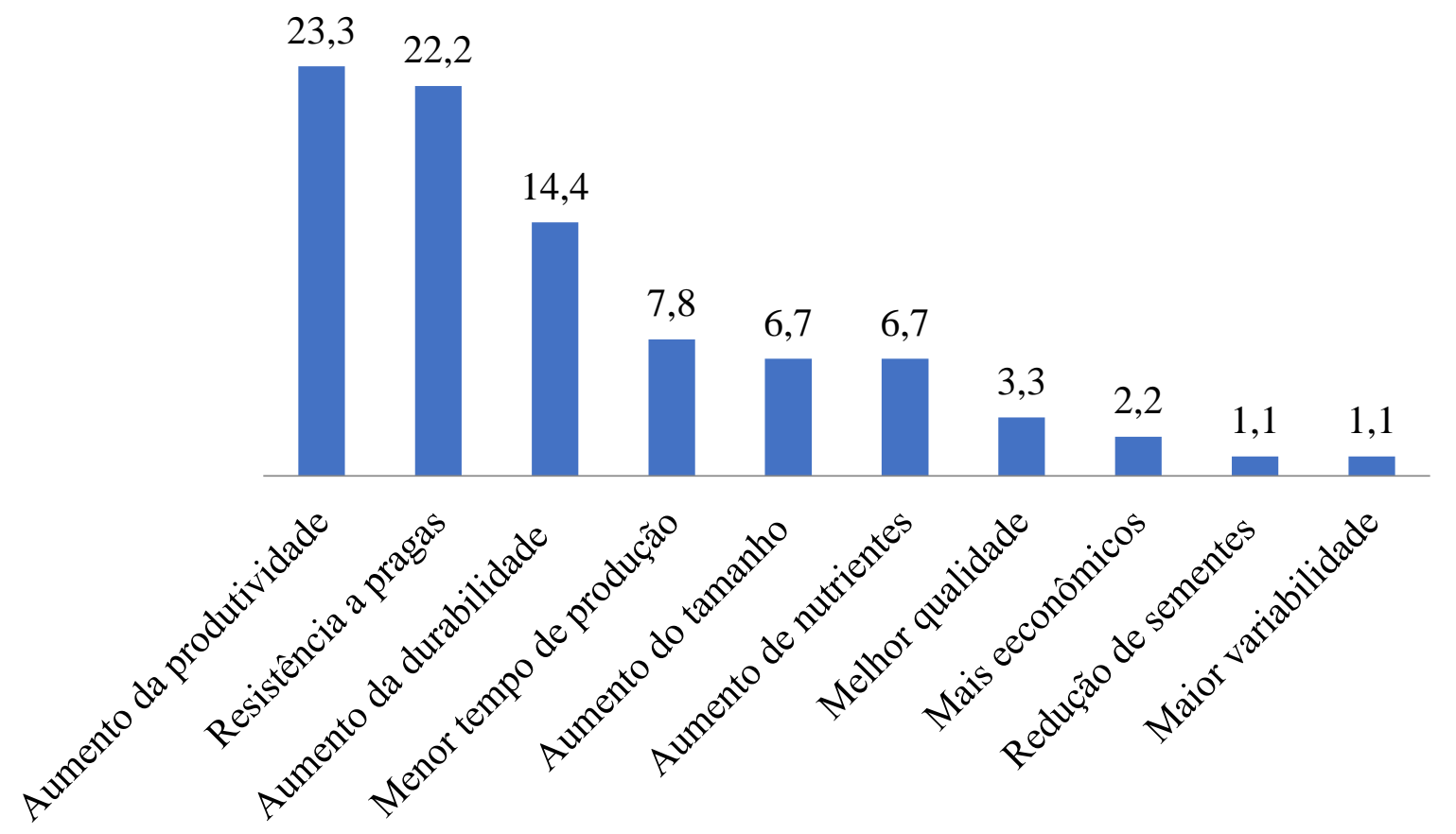

Figura 1: Vantagens do uso dos produtos transgênicos.

$\mathrm{Na}$ sequência, foram citadas também as vantagens "aumento da durabilidade", "menor tempo de produção", "aumento do tamanho" e "aumento dos nutrientes", o que são fatores essenciais quando se considera a obtenção de produtos agrícolas. Com estes benefícios, é possível obter alimentos funcionais, em maior quantidade melhor qualidade, o que mostra que, quanto aos benefícios dos transgênicos, os alunos mostram informações amplas e consistentes. 
Outras opções foram também indicadas, porém, com menores citações, sendo estas "melhor qualidade", "mais econômicos", "redução de sementes" e "maior variabilidade". Estas vantagens, apesar de serem também observadas nos produtos transgênicos, podem ser obtidas por meio de métodos clássicos de melhoramento genético, sem necessitar de manipulação molecular de DNA ou da inserção de genes de outros organismos.

É viável ressaltar que a opção "variabilidade genética" é essencial para o desenvolvimento de pesquisas com qualquer que seja a espécie, contudo, o desenvolvimento de transgênicos não contribui significativamente para o aumento desta. Isto ocorre porque ao criar um produto transgênico, apesar de serem inseridas características favoráveis, as características que podem não ser de interesse são eliminadas, o que resulta na perda de variabilidade genética.

Ao se perguntar aos alunos se estes conheciam algum produto transgênico, 88,9\% dos entrevistados respondeu que "sim". Ao pedir que estes citassem exemplos desses produtos, pode-se obter os alimentos presentes no Quadro 1. Contudo, por nem todos os alimentos citados serem transgênicos, as respostas foram categorizadas para facilitar o entendimento.

Quadro 1. Categorias formadas com produtos indicados pelos alunos como transgênicos.

\section{Categorias \\ Produtos transgênicos comercializados no Brasil \\ Produtos transgênicos não comercializados no Brasil \\ Produtos que não são transgênicos}

\section{Produtos citados}

Milho, soja, óleo, salgadinhos, bolachas, macarrão, carne bovina, manteiga e insulina.

Trigo, feijão, arroz, pimentão e mamão.

Alface, ervilha, laranja, frutas sem sementes, legumes, leite, chocolate e enlatados.
Com respostas bem variadas é possível observar que uma boa parte dos produtos transgênicos citados pelos alunos tem associação com o consumo do dia-a-dia. Para estes, destaca-se principalmente o milho e a soja, além de seus subprodutos como os salgadinhos e o óleo que também foram citados. Estas informações levam a entender que a associação dos transgênicos com o dia a dia dos alunos é algo essencial para a consolidação do conhecimento.

Alguns alunos indicaram produtos que são transgênicos, mas que não são comercializados no Brasil. Isto pode ter se dado pôr os mesmos já terem ouvido falar sobre tais produtos, não tendo estes sido citados pela associação com o consumo do dia a dia. Deve-se ainda considerar o fato dos alunos terem citado esses produtos, porém, sem a certeza de que realmente eram transgênicos.
Essa possibilidade é reforçada pelo fato dos alunos terem citado produtos que não são transgênicos ou que ainda estão em estudos para o seu lançamento. Nesse contexto, forram citados alimentos que são melhorados geneticamente mas que não são transgênicos, como algumas hortaliças e as frutas sem sementes. Isto pode ter se dado pôr os alunos não terem um amplo conhecimento sobre os transgênicos, com já mencionado anteriormente, e com isso terem dificuldades na associação dos mesmos.

Perguntou-se aos alunos, segundo o conhecimento destes, quais produtos transgênicos eram produzidos no Brasil, podendo os resultados ser observados no Quadro 2. Os produtos mais citados foram o milho e a soja, o que se atribui não apenas ao conhecimento do produto primário, mas também dos seus derivados, como salgadinhos de milho, milho enlatado, proteína de soja e óleo de soja, os quais, por 
serem derivados de matéria prima transgênica, são também considerados transgênicos.

Quadro 2. Indicação de produtos produzidos no Brasil que os alunos consideram transgênicos.

\begin{tabular}{|l|c|}
\hline \multicolumn{1}{|c|}{ Produtos } & Indicação (\%) \\
\hline Milho & 47,5 \\
\hline Soja & 27,7 \\
\hline Tomate & 8,9 \\
\hline Arroz & 5,9 \\
\hline Feijão & 4,0 \\
\hline Algodão & 3,0 \\
\hline Frutas e legumes & 2,0 \\
\hline $\begin{array}{l}\text { Trigo, carne, farinha, óleo, } \\
\text { manteiga, cuscuz, ervilha e cana- } \\
\text { de-açúcar }\end{array}$ & 1,0 \\
\hline
\end{tabular}

Esses resultados mostram que os entrevistados possuem conhecimentos sobre os produtos transgênicos que são produzidos no Brasil, no qual estão no pódio a soja, o milho e o algodão, sendo os três citados pelos estudantes durante a pesquisa, apesar do algodão contar com uma indicação relativamente baixa. Esses alimentos são cultivados em larga escala, sendo a soja o produto mais cultivado, representando a versão transgênica $92 \%$ de toda a soja produzida no pais, o que, para o milho está na ordem de 90\% e para o algodão 47\% (EMBRAPA, 2013).

Ao se fazer a indagação, considerando os transgênicos produzidos no Brasil, mais uma vez foram citados produtos que não são transgênicos, como as frutas e legumes que foram citadas de maneira generalizada. Isto ressalta a necessidade dos alunos se aprofundarem nesse assunto, uma vez que o mesmo diz respeito a algo de grande presença nas suas vidas, que é a alimentação.

Essas informações mostram que $\mathrm{O}$ conhecimento dos alunos é influenciado por vivências que estes possuem do dia a dia. Ao se buscar saber como os alimentos modificados são conhecidos por estes, fica claro que suas percepções se embasam naquilo que os mesmos vão aprendendo ao longo de suas vidas. Pois exemplos citados no meio acadêmico, informações obtidas por meio das mídias e experiências práticas os levam a fazer suas indicações quando indagados.

\section{CONCLUSÃO}

Diante dessa pesquisa fica claro que transgênicos é um tema que requer maior atenção no âmbito acadêmico, o qual precisa ser melhor trabalhado nos cursos de Ciências Biológicas. Deficiências devem ser superadas, sobretudo, no que diz respeito a conceituação dos transgênicos e a diferenciação destes dos produtos que são oriundos apenas de técnicas de melhoramento genético clássico.

Contudo, ressalta-se que a associação dos produtos transgênicos com o cotidiano dos alunos é um ponto que pode favorecer o aprendizado, pois estes apresentam conhecimentos assertivos quando associam tal tema com algo presente na alimentação do seu cotidiano. Dessa forma, ainda há muito o que se conhecer sobre os transgênicos, devendo todas as formas de aprendizado ser promovidas.

\section{REFERÊNCIAS}

Creswell JW. Projeto de pesquisa: métodos qualitativo, quantitativo e misto. 3nd ed. Porto Alegre: Artmed; 2010.

Embrapa. Produtos Transgênicos na Agricultura, 2013. Disponível em: http://www.portalembrapa.br/agricultura.

Embrapa. Recursos Genéticos e Biotecnologia, 2020. Disponível em: http://www.portalembrapa.br/biotecnologia.

Embrapa. Transgenia: quebrando barreiras em prol da agricultura brasileira, 2014. Disponível em: http://www.portalembrapa.br/transgênicos.

Ferreira DC. A bioética na tomada de decisão na atenção primária à saúde. Revista brasileira de 
educação medica. 2018;39:479-485. Disponível em:

http://www.scielo/revistabrasileiradeeducaçao medica.com.

Gil AC. Métodos e técnicas de pesquisa social. 6nd ed. São Paulo: Editora Atlas; 2012.

Lacey HA. Controvérsia sobre os transgênicos: questões científicas e éticas, Aparecida, 2009.

Mapa. Ministério da agricultura, pecuária e abastecimento. Organismos Geneticamente Modificados, 2019. Disponível em: http://www.agricultura.gov.br/vegetal/organis mos-geneticamente-modificados.

Nóbrega E. Estratégias metodológicas adotadas nas pesquisas de iniciação científica premiada na UFPB. 2009;14:170-190. Disponível em: https://periodicos.ufsc.br/index.php/eb/articl e/view/1518-2924.2009v14n27p170/19693.

Pedrancini VD. Saber Científico e conhecimento espontâneo: opiniões de alunos do ensino médio sobre transgênicos. Revista Ciência \& Educação. 2009;14:135-146.

Schwartžman $A S$. contribuição da educação para o progresso social, 2018. Disponível em: https://periodicos.fundaj.gov.br/CIC/article /view/1721.

Silva JD. Plantas Transgênicas. Cadernos PDE, 2010, volume II. Disponível em: http://www.diaadiaeducaçao.pr.gov.

Udo R. Transgênicos a polêmica. 2015. Disponível em: http://www.abcdasaude.com.br/nutriçao/trans genicos-a-polemica.

Villani A. O aperfeiçoamento da competência profissional do professor de ciências. 5nd ed. São Paulo: Artmed; 2009.

Zanini LEA. Os direitos do consumidor e os organismos geneticamente modificados. Revista de doutrina. 2015;48:30-45. 